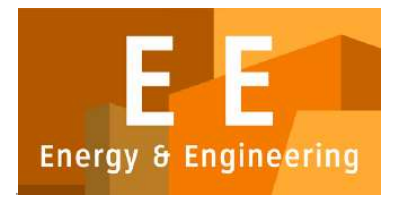

PAPER - OPEN ACCESS

\title{
Perencanaan Intensitas Pembangunan Pada Desa Wisata Tongging
}

\author{
Author $\quad$ : Nurlisa Ginting dan Ulia safitri \\ DOI $\quad: 10.32734 /$ ee.v3i1.863 \\ Electronic ISSN $\quad: 2654-704 X$ \\ Print ISSN : $2654-7031$
}

Volume 3 Issue 1 - 2020 TALENTA Conference Series: Energy \& Engineering (EE)

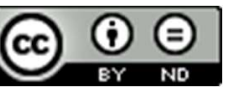

This work is licensed under a Creative Commons Attribution-NoDerivatives 4.0 International License.

Published under licence by TALENTA Publisher, Universitas Sumatera Utara

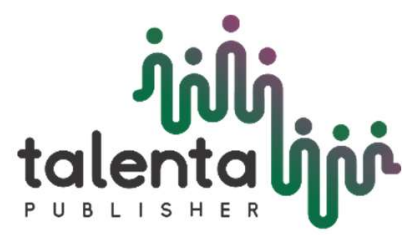




\title{
jibli and \\ EE Conference Series 03 (2020)

\section{Perencanaan Intensitas Pembangunan Pada Desa Wisata Tongging Development Intensity Planning in the Tongging Tourism Village}

\author{
Nurlisa Ginting ${ }^{a, b, c,}$, Ulia Safitria* \\ ${ }^{a}$ Master's Degree Program of Architecture, Faculty of Engineering, Universitas Sumatera Utara, Medan, Indonesia \\ ${ }^{b}$ Monitoring Centre for Sustainable Tourism Observatory (MCSTO) Universitas Sumatera Utara, Medan, Indonesia \\ ${ }^{c}$ Toba Lake \& Sustainable Tourism Working Group, Universitas Sumatera Utara, Medan, Indonesia \\ nurlisa@usu.ac.id, uliasafitri93@gmail.com
}

\begin{abstract}
Abstrak
Desa Tongging merupakan salah satu desa di Kabupaten Karo yang menjadi tujuan utama wisatawan sehingga potensial untuk dikembangkan sebagai suatu desa wisata. Namun sangat disayangkan kondisi intensitas pembangunan di Desa Tongging belum ditata melalui suatu perencanaan. Hal ini menyebabkan kondisi visual kawasan yang ada tidak mendukung Tongging sebagai desa wisata. Perencanaan intenstitas pembangunan Desa Tongging yang tepat adalah dengan berdasarkan pariwisata berkelanjutan. Kajian perencanaan perlu dilakukan dengan analisis terhadap KDB, GSB, GSS, dan ketinggian bangunan. Penelitian ini dilakukan dengan menggunakan data hasil observasi lapangan yang dianalisa secara kualitatif. Kajian ini bertujuan untuk menghasilkan perencanaan intensitas pembangunan dalam upaya pengembangan desa wisata tongging yang berkelanjutan.
\end{abstract}

Kata kunci: Intensitas pembangunan, Desa wisata, Tongging

\begin{abstract}
Tongging Village is one of the villages in Karo Regency which is the main destination for tourists so that it has the potential to be developed as a tourist village. However, it is unfortunate that the condition of the intensity of development in Tongging Village has not been arranged through a plan. This causes the visual condition of the area does not support Tongging as a tourist village. The proper planning for the development of the Tongging Village is based on sustainable tourism. Planning studies need to be done with an analysis of KDB, GSB, GSS, and building heights. This research was conducted using data from field observations that were analyzed qualitatively. This study aims to produce planning the intensity of development in an effort to develop a sustainable tongging tourism village.
\end{abstract}

Keywords: Development intensity, Tourism Village, Tonggin

\section{Pendahuluan}

Pariwisata merupakan salah satu sumber devisa yang sangat besar bagi negara yang mampu membantu pembangunan dan perekonomian negara. Desa Tongging memiliki potensi untuk dikembangkan menjadi desa wisata. Salah satu bentuk wisata unggulan daerah yang sangat popular dikembangkan dewasa ini adalah desa wisata (Hermawan, 2016). Desa tongging terletak pada Kecamatan Merek, Kabupaten Karo, Sumatera utara yang memiliki luasan wilayah $4.50 \mathrm{~km} 2$ berjarak sekitar $40 \mathrm{~km}$ dari kota Brastagi. Desa tongging memiliki potensi wisata yang dapat dinikmati wisatawan baik wisatawan domestik maupun mancanegara dengan tujuan wisata yang sangat menarik seperti bentangan alam, danau, lahan pertanian dan pegunungan. Akan tetapi desa tongging masih memiliki permasalahan dalam penataan bangunan, bangunan pada desa tongging tidak memiliki keteraturan sehingga tidak menimbulkan visual yang baik bagi wisatawan yang berkunjung. Tujuan dalam penelitian ini adalah untuk merencanakan intesintas pembangunan yang baik bagi Desa Tongging agar menjadi desa wisata yang menarik bagi wisatawan.

\section{Tinjaun pustaka}

\subsection{Intensitas pembangunan}

Intensitas pembangunan merupakan hal penting dalam perencanaan dan perancangan Desa Tongging menjadi desa wisata. Intensitas pembangunan berkaitan erat dengan aspek pembentuk fisik pada massa bangunan yaitu, ketinggian, pemunduran, sempadan dan coverage bangunan, serta konfigurasi bangunan (Shirvani, 1985).Perubahan penggunaan lahan mencakup perubahan fungsi (landuse) karena terjadinya perubahan jenis kegiatan, intensitas (mencakup perubahan KLB, KDB) dan ketentuan teknis masa bangunan (bulk) antara lain berupa perubahan Garis Sempadan Bangunan, tinggi bangunan dan perubahan minor lainnya yang tidak mengubah fungsi dan intensitasnya. Intensitas bangunan gedung adalah ketentuan teknis tentang kepadatan dan ketinggian bangunan

(c) 2020 The Authors. Published by TALENTA Publisher Universitas Sumatera Utara

Selection and peer-review under responsibility of Seminar Nasional Kearifan Lokal V 2020

p-ISSN: 2654-7031, e-ISSN: 2654-704X, DOI: 10.32734/ee.v3i1.863 
gedung yang dipersyaratkan pada suatu lokasi atau kawasan tertentu, yang meliputi koefisien dasar bangunan (KDB), koefisien Lantai bangunan (KLB), Garis sempadan bangunan (GSB), Garis sempadan samping (GSS) dan ketinggian bangunan

KDB atau buliding coverage ratio adalah angka persentase berdasarkan perbandingan jumlah luas lantai dasar bangunan terhadap luas tanah perpetakan/daerah perencanaan yang dikuasai sesuai rencana tata ruang kota. Secara matematis, KDB dapat dinyatakan dalam persamaan presentase luas lantai bangunan dibagi dengan luas paling.GSB atau building demarcation line adalah garis batas dalam mendirikan bangunan di suatu persil atau petak yang tidak boleh dilewatinya. Menurut (Viasari dan Osly, 2017) Garis sempadan (muka) bangunan/GSB merupakan jarak dinding terluar bangunan/batas persil bagian depan terhadap jalan. pada bagian muka bangunan merupakan jalan satu arah, maka hitungan batas as jalan untuk garis sempadan adalah sampai ujung jalan. jika pada depan bangunan tersebut merupakan jalan dua arah, maka hitungan batas as jalan berada di bagian tengah jalan atau pada median jalan. Garis sempadan bangunan harus adanya ruang terbuka yang membatasi antara jalan dan bangunan untuk menambah keamanan.

KLB merupakan ukuran yang menunjukkan proporsi total luas lantai suatu bangunan dengan luas kapling dimana bangunan tersebut berdiri. Secara matematis, KLB dapat dinyatakan dengan persamaan presentase total luas lantai bangunan dibagi luas kapling. Sedangkan Tinggi bangunan atau building elevated merupakan jumlah lantai penuh dalam satu bangunan dihitung mulai lantai dasar sampai puncak atap suatu bangunan, yang dinyatakan dalam meter; atau TB adalah angka yang membatasi ketinggian suatu bangunan yang dapat berupa lapis/tingkat bangunan, atau dalam satuan ketinggian (meter).

\subsection{Studi kasus}

Dusun Sade merupakan dusun yang terletak di Desa Rembitan, Kecamatan Pujut, Kabupaten Lombok Tengah, Pulau Lombok. Desa dusun sade merupakan desa adat dengan bangunan berarsitektur tradisional. Intensitas pembangunan pada desa sade tetap mempertahankan bangunan adat yang mana bangunan tersebut merupakan simbol dari desa dusun sade. Sehingga apabila ingin melakukan pembangunan maka pembangunan harus mengikuti langgam arsitektur tradisional dusun sade.
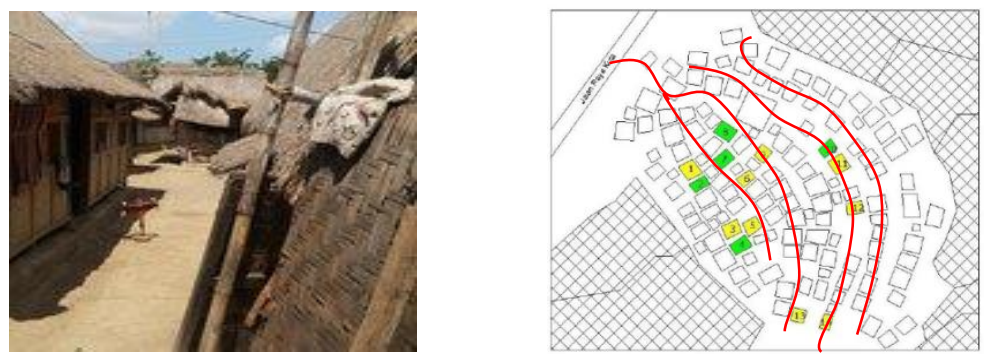

Gambar 1. Intensitas pembangunan Desa dusun sade

\section{Metodelogi}

Kawasan desa tongging terletak di wilayah administrasi Kecamatan merek, Kabupaten karo, Sumatera utara. Perencanaan desa wisata tongging ini dibatasi oleh lahan perkebunan bagian utara, pemukiman sebelah barat, bentangan danau toba sebelah barat, dan perbukitan sebelah timur (Gambar.1) 


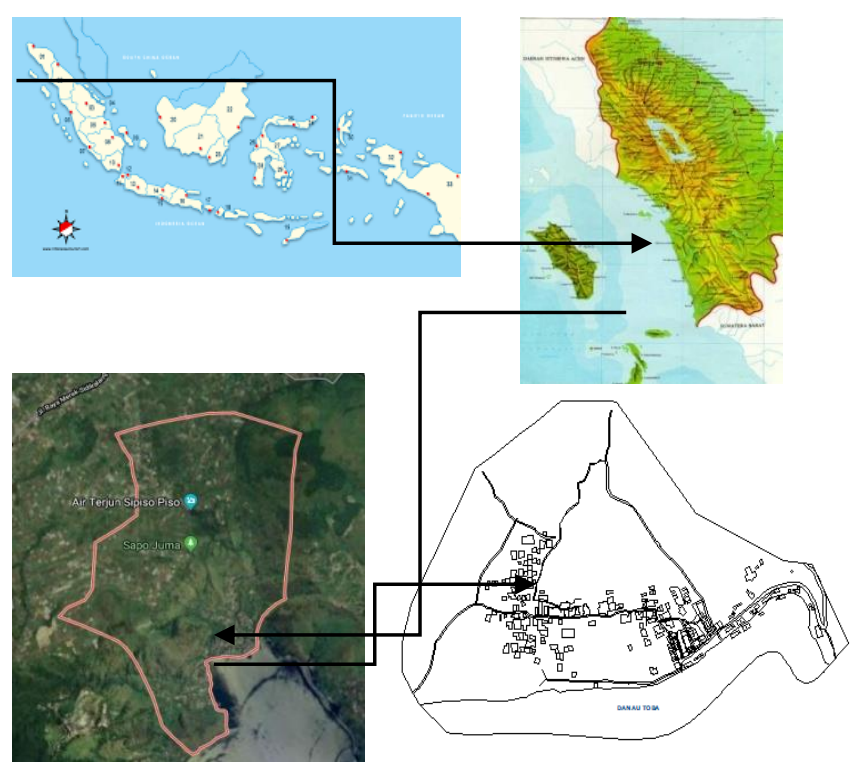

Gambar 2. Kawasan perencanaan Intensitas pembangunan Desa Tongging

Pengumpulan data yang dibutuhkan dalam penyelesaian penelitian ini menggunakan metoda kualitatif. Penelitain ini juga didasari kajain putaka mengenai intensitas pembangunan. yang dimana studi kasus yang diangkat merupakan desa wisata sade, desa wisata penting sari dan desa wisata kutuh. Data-data yang dubutuhkan pada penelitian ini merupakan data primer berupa dokumentasi dan hasil wawancara kepala desa sedangkan data skunder berupa hasil studi literatur. Berdasarkan hasil kajian studi literatur dan hasil observasi lapangan maka dilakukan perencanaan yang bertujuan untuk menjadikan desa tongging sebagai desa wisata yang berkelanjutan.Sehingga mengahasilkan potensi dan solusi kawasan perencanaan intensitas pembangunan pada Desa Tongging.

\section{Hasil dan pembahasan}

Kawasan Desa Tongging pada umumnya memiliki intensitas pembangunan yang masih rendah. Ketinggian bangunan rata-rata 1 lantai dan kepadatan bangunan rendah $<50 \%$ kecuali pada kawasan pusat desa untuk daerah permukiman $50-70 \%$. Belum ada peraturan yang mengatur tentang ketentuan intensitas pembangunan pada kawasan desa tongging. Peraturan RDTR untuk kecamatan merek sampai saat ini belum disusun. Satu-satunya aturan yang mengatur tentang ketentuan pembangunan pada kawasan desa tongging adalah pada perpres RTR KSN Danau Toba nomor 81 tahun disebutkan bahwa pada area permukiman Kawasan Wilayah Terbangun (KWT) maksimum adalah 50\% dan ketinggian bangunan maksimum 1-2 lantai. Sempadan terhadap Danau sebesar 50 100 meter dan sempadan terhadap sungai sebesar 50 meter. Intensitas pembangunan dengan kepadatan tinggi pada kawasan komersial dan kawasan permukiman penduduk sekitar dermaga. Sebelumnya kawasan ini juga sudah padat dan merupakan titik konsentrasi penduduk desa tongging. Pada kawasan ini diterapkan KDB $70-90 \%$ dengan jumlah lantai bangunan maksimum 3 lantai.
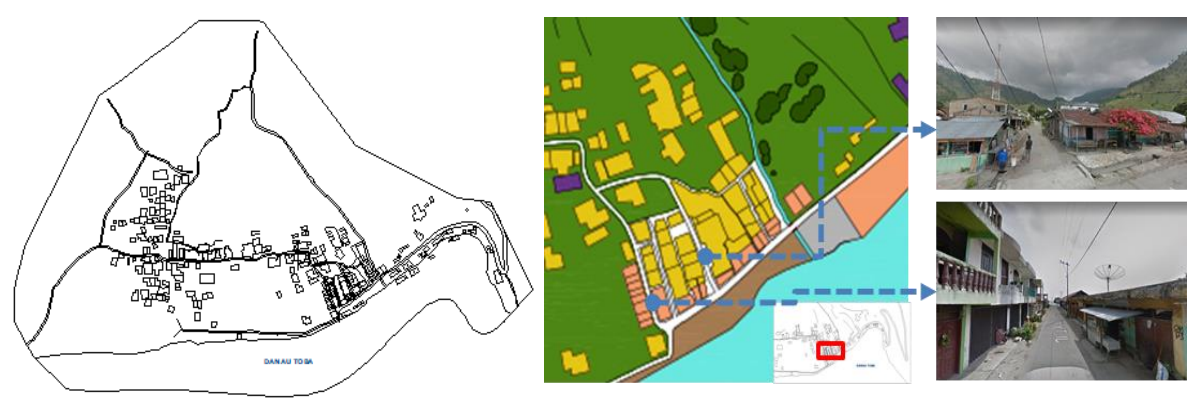

Gambar 3. Lokasi perencanaan dan perancangan Desa Tongging 
Kondisi lokasi eksisting pada desa tongging masih belum tertata, pada lokasi pintu masuk bangunan relatif padat. Jika ditinjau dari intensitas pembangunan, KDB Pada kawasan ini diterapkan KDB 70 - 90\% dengan jumlah lantai bangunan maksimum 3 lantai. Garis sempadan jalan pada terhadap jalan lingkungan adalah 0 GSB. Kondisi ini mengakibatkan intensitas pembangunan pada kawasan ini tidak teratur, terutama pada area permukiman dan komersial. Intensitas pembangunan dari studi banding desa tongging memiliki kesamaan dengan pola pemukiman desa dusun sade yang relatif padat. Akan tetapi intensitas pembangunan pada desa dusun sade menerapkan peraturan adat desa dusun sade yang mempertahankan bangunan dengan tidak melanggar peraturan, kondisi ini yang akan diterapkan pada desa tongging yang tetap mempertahankan bangunan permukiman eksisting akan tetapi adanya perancangan intensitas pembangunan dengan cara memperbaiki kondisi intensitas pembangunannya yang lebih baik dan tetap mengikuti peraturan peraturan pemerintah yang ada. Perancanaan intensitas pembangunna pada desa tongging ini dilakukan dengan tetap mempertahankan bangunan pemukiman eksiting, akan tetapi untuk zona ini yang merupakan zona kepadatan tinggi memiliki koefisien dasar bangunan (KDB) yaitu 70\%-90\% dengan garis sempadan bangunan (GSB) yaitu 3, 5 meter. Ketinggian bangunan 3 lantai yang memiliki garis sempadan samping (GSS) yaitu 0 meter. Untuk Intensitas pembangunan dengan kepadatan sedang pada kawasan permukiman penduduk dan kawasan fasilitas umum. Pada kawasan ini diterapkan KDB 50 - $70 \%$ dengan jumlah lantai maksimum 2 lantai

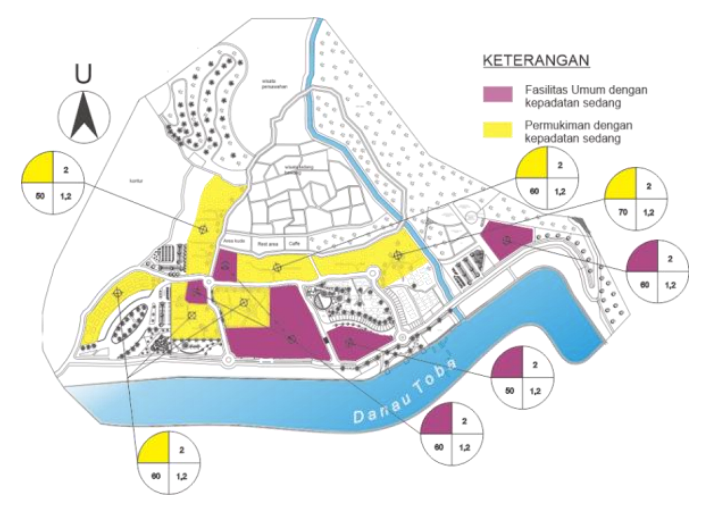

Gambar 4. Permasalahan Intensitas Bangunan Desa Tongging

Menetapkan area sempadan danau mulai dari bibir danau sampai sisi jalan yang menyusuri area tepi danau sebagai Fungsi hijau/ RTH dengan lebar 30 - 50 meter.Menetapkan area sempadan sungai dengan jarak 5-10 meter dari tepi sungai sebagai fungsi hijau/RTH.Area perbukitan yang memiliki kemiringan lebih dari 45 derajat direncanakan sebagai fungsi hijau.

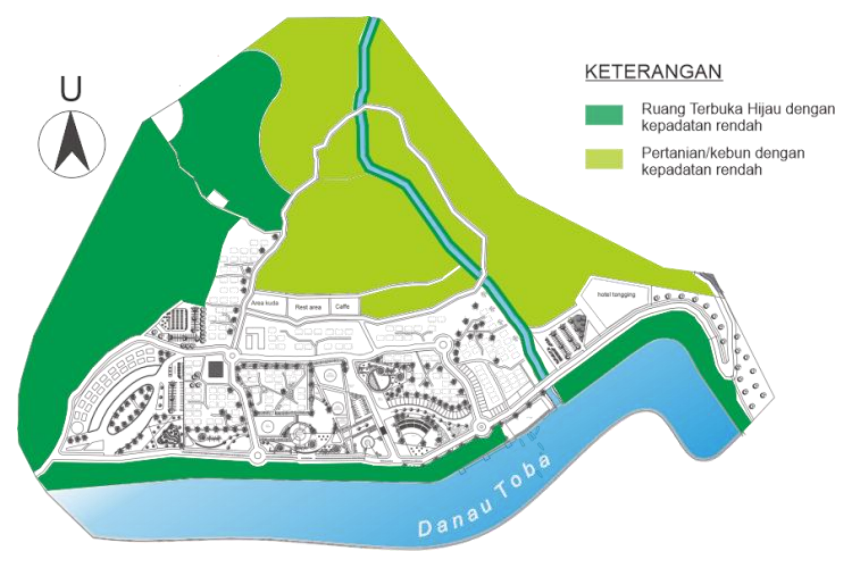

Gambar 5. Permasalahan Intensitas Bangunan Desa Tongging

Bangunan yang berada di Desa tongging tidak memiliki garis sempadan bangunan (GSB=0), Ruang antara bangunan dan jalan dijadikan akses jalan. Ketinggian bangunan pada kondisi eksisting adalah bangunan 1 lantai bangunan yang memiliki ketinggian lebih dari 1-2 lantai pada umumnya adalah bangunzan dengan fungsi sebagai fungsi sebagai perumahan dan pertokoan. KDB yang terdapat pada kondisi eksisting kawasan perancangan maksimumi 70\%, Kepadatan bangunan yang terdapat di tepi sungai pada umumnya adalah bangunan komersil berupa tempat makan, dan perumahan. 


\section{Kesimpulan}

Melalui perencanaan kawasan Desa Tongging pada umumnya memiliki intensitas pembangunan yang masih rendah. Ketinggian bangunan rata-rata 1 lantai dan kepadatan bangunan rendah $<50 \%$ kecuali pada kawasan pusat desa untuk daerah permukiman 50 $70 \%$. Sebagai desa wisata diharapkan mampu membatasi jumlah pembangunan yang sesuai untuk tujuan mengendalikan pemanfaatan lahan dan garis sempa dan bangunan secara terencana dan mampu mengembalikan intensitas pembangunan sesuai dengan arahan pemerintah daerah melalui RDTR, Penentuan KDB (koefisien Dasar Bangunan), GSB (Garis Sempadan bangunan), GSS (Garis Sempadan Sungai) dan Mempertahankan ketinggian maksimal bangunann hanya mencapai 2 lantai.

\section{Referensi}

[1] Shirvani, H. (1985). The urban design process. Van Nostrand Reinhold Company.

[2] Hendrojogi, W. (2012). Arahan Pengaturan Dan Pengendalian Bangunan Di Kecamatan Pinang Kota Tangerang. Jurnal Sains dan Teknologi Indonesia, 10(1).

[3] Hermawan, H. (2016). Dampak pengembangan Desa Wisata Nglanggeran terhadap ekonomi masyarakat lokal. Jurnal Pariwisata, 3(2), $105-117$.

[4] Viasari, L., \& Osly, P. J. (2017). Analisis Garis Sempadan Bangunan (Studi Kasus Jalan Raya Pajajaran Kota Bogor). Jurnal Infrastruktur, 3(2), 71-80. 